\title{
Creating a sustainable future? the working life of creative workers in Vienna
}

\author{
Sybille Reidl \\ Helene Schiffbänker \\ Hubert Eichmann
}

Sybille Reidl is a researcher at the Joanneum Research Centre at the Institute of Technology and Regional Policy in Vienna, Austria.

Helene Schiffbänker is a senior researcher at the Joannem Research Centre at the Institute of Technology and Regional Policy in Vienna, Austria.

Hubert Eichmann, is a senior researcher at Forschungs- und Beratungsstelle Arbeitswelt (FORBA), the Working Life Research Centre in Vienna, Austria.

\begin{abstract}
This article looks at the sustainability of work arrangements in Vienna's creative industries. Based on a survey of over 900 people who work in five sub-sectors (advertising, architecture, graphics/design/fashion, film/video/broadcasting and multimedia), it finds that there is significant pressure on those working in these industries. This results mainly from the fact that most are self-employed and consequently their guarantee of future work is insecure and they lack strategies to develop their own micro-businesses. The respondents have, however, developed coping strategies to deal with these pressures. In general, therefore, those with a high risk strategy in combination with high levels of work autonomy are more satisfied than creative workers who are employed and have a steady income but little decision-making freedom. Despite this, issues such as social security raise doubts about the future sustainability of their work. Further information about the project can be found on www.forba.at/kreativbranchen-wien.
\end{abstract}

\section{Introduction}

The creative industries have generated increasing public interest in recent years, with the main focus on their economic and employment potential and on the systematisation of the creative industries sector. A significant impetus came from the European Commission (1998), which identified an employment potential of over four million jobs in the creative industries in Europe. The 'Creative Industries Mapping Document' (2001), funded by the British Departmentof Culture, Media and Sport (DCMS) provided a detailed (and continually updated) picture of the economic significance and employment relevance of many the subsectors of the creative industries. There have also been Austrian studies highlighting the economic and employment potential of the creative industries, e.g. two reports on the creative 
industries in Austria by KMU-Forschung Austria/IKM (2003 and 2006) and research into the economic potential of the creative industries in Vienna by WIFO/mediacult/ Kulturdokumentation (2003). Outside Vienna, several Austrian regions (e.g. Linz, Tyrol) have tried to assess the employment and economic potential of the creative industries (Lechner/Phillip 2006, Kalmar et al. 2005). This research has focused mainly on the development of economic clusters and on employment potential, but it also provides basic information on forms of employment and the availability of skills.

These sectors depend on knowledge and skills which are built up over time. Continuity of career patterns and sustainable working conditions are therefore of paramount importance. However, very little research has been done on the quality of work and life or on career patterns in the creative industries. The few Austrian studies available (overview by Schiffbänker/Mayerhofer 2003) relate more to classical groups of artists (e.g. in the fine or performing arts). Apart from this, most research has focused on the 'social situation', i.e. relatively easily measurable features of this type of work: its high educational requirements, its high ratio of self-employed or atypical workers with insecure incomes, at least in part, and the need for supplementary parttime or full-time employment in unrelated jobs. Therehave been almost no primary surveys of the socio-economic and socio-cultural aspects of work/life quality in broader sections of the creative industries in the private sector - e.g. in architecture, graphic design or fashion.

As with other knowledge-intensive industries, for broader creative industry sectors (as well as for artists in the narrow sense), a structural economisation is to be assumed inasmuch as these groups - regardless of their employment status - are becoming ever more directly subject to market constraints. In this process individual job descriptions are becoming broader and beginning to merge with others, e.g. the separation between creative work and customer work is losing its significance (for example among software developers, architects and designers), as are clear vocational demarcations. Consequently, research on the quality of work in knowledge-based and creative jobs has found a variety of different situations ranging from self-determination and successful 'enterprising selves', to self-exploitation and insecure forms of work (Gottschall/Betzelt 2001, Pongratz/Voß 2003). But it is precisely among creative workers that insecure working conditions are compensated for by greater autonomy, intrinsic motivation potential and highly developed lifestyles and concepts of the self. This raises the question of sustainability and makes it necessary for studies of creative or knowledge-based workers, and for policy recommendations to take greater account of the connections between the objective features of this work and its subjective meanings and needs ${ }^{1}$.

1 It is difficult to classify 'creative' work in advertising, architecture, design etc. according to a clearcut definition of creativity. Instead, as in most empirical research, we focus on people working in selected 'creative' industries and/or occupations. Respondents from companies of a certain industry (e.g. advertising agencies) may produce some kind of artistic output (e.g. as graphic artists) or not (e.g. as customer adviser). Both the creative/artistic and non-creative/artistic work examined in our study refer to knowledge intensive work. Using this approach (sectors and occupations) we avoid the need to develop precise descriptions of creative or knowledge work (as well as the question whether Richard Florida's definition of a 'creative class' may be problematic). Despite this, it is possible to classify the industries we analyse as 'professional applied creative services', predominantly falling outside classical definitions of 'artists' (cf. Hill \& Johnson 2003). 


\section{Empirical base}

Taking account of this context, the research project 'Sustainable Work and Employment in Vienna's Creative Industries', funded by WWTF (the Vienna Science and Technology Fund) was set up to address the following questions: How sustainable or insecure is work in the creative professions in Vienna? What conditions promote or hinder access to employment and job retention? To what extent are resources available to cope with or avoid excessive workloads? What differences are evident between men and women and between different subsectors and forms of work and activity? What are the key features of successful arrangements for sustainable work and employment?

The research project, conducted primarily by FORBA and Joanneum Research, focused on the sustainability of existing jobs in subsectors of Vienna's creative industries. This involved a detailed investigation of business processes, working conditions, careers and patterns of coping with work in the context of institutional and sector-specific conditions, with the essential point of reference being the sustainability of work and employment in creative industries. Sustainability in this context is understood as an enduring quality of life and work. This entails a difficult balance between resources, requirements and demands. The resources that were taken into account with respect to sustainability in this study were: economic resources (income, employment and social security); social resources (social capital, professional and private networks); time resources (working time, private time, reconciliation); knowledge resources (competences, vocational training); health resources (workload and coping strategies); and biographical resources (continuity of career perspectives, multiple jobs).

The target groups we chose to analyse were in the creative industries outside the classical branches of the arts, which are involved in the 'applied' sectors and can predominantly be classified as lying in the private sector of the creative industries: advertising; architecture; graphics/design/fashion; film/video/broadcasting; and multimedia.

At the beginning of the project, a separate analysis of the five different subsectors was carried out (see Eichmann et al., 2005). As expected, this showed a high level of heterogeneity in and between the sectors, demonstrating that 'creative industries' is just an umbrella term for funding policies. A common experience among those involved in the creative industries was a strong tendency towards 'self-economisation' (cp Pongratz and Voß 2003) by which we mean a need for workers to invest in their own work and career development. Sustainability in these occupational fields is not strongly institutionalised, which may result from the fact that labour supply is larger than demand. Four of the five sectors (architecture being the exception) are weakly regulated, dominated by project work and with unclear career prospects. These features, together with the highly demanding nature of the work, would suggest that working conditions in the creative industries are not very sustainable. For more detailed information about working and living conditions in the creative industries, we carried out fifty problem-centred 
qualitative interviews and a standardised quantitative survey. The results of this quantitative survey are the main topic of this article.

\section{Background to the study}

In 2005 an online survey was conducted in the five subsectors examined in this study. The questionnaire was distributed via multipliers (interest group representatives, educational institutions, databases). Despite the support of numerous multipliers, it was not possible to reach certain segments of the fields being studied, in particular creative workers in Vienna who are not included in the relevant databases. Because of this investigation method, which was chosen because of the uncertainty regarding the total numbers, it cannot be assumed that the survey is representative. In terms of basic research, however, the findings provide important information on the employment situation of those working in the selected five subsectors.

The study involved both people working in the creative industries and those working in creative occupations in other industries in Vienna as presented in Table 1 . Those in the creative industries include both people whose jobs classify them as creative workers (field A) and people who have other types of job in these industries, for instance managers (field B). In total, 82 per cent of those who completed the questionnaire belonged in these two categories. It was also possible to contact creative workers outside the creative industries through professional associations and interest group representatives, for instance graphic designers working in the banking industry (field C) and these represented 18 per cent of our sample. This classification follows the methodology of Bernard Casey (1999).

\section{Table 1: Classification of the creative sector by activity and industry}

\begin{tabular}{|c|c|c|c|}
\hline \multirow{4}{*}{$\begin{array}{l}\text { Creative } \\
\text { activities }\end{array}$} & \multicolumn{3}{|c|}{ Creative industries } \\
\hline & & yes & no \\
\hline & yes & $\begin{array}{l}\text { Field A - examples: Cam- } \\
\text { erawoman in a film production } \\
\text { company; } \\
\text { copywriter in an advertising } \\
\text { agency }\end{array}$ & $\begin{array}{l}\text { Field C - examples: } \\
\text { Architect in the public services; } \\
\text { Graphic artist in the banking } \\
\text { industry }\end{array}$ \\
\hline & no & $\begin{array}{l}\text { Field B - examples: } \\
\text { Marketing manager of a de- } \\
\text { sign studio; } \\
\text { Secretary in an architect's } \\
\text { office }\end{array}$ & Outside the creative sector \\
\hline
\end{tabular}

Source: FORBA and Joanneum Research, 2006

\section{People employed in the creative industries and the basic terms on which they work}

A total of 910 people from the fields of architecture, design/graphics/fashion, film/ broadcasting/video, software/multimedia/internet and advertising responded to the 
questionnaire. The data were weighted in accordance with the job count (Austria Statistics, 2004) and an expert estimate of the size of each sector. One third of the respondents were female and two thirds male. The picture that emerges from the data is of a small business structure, with almost half of the respondents working in companies with fewer than five employees. Figure 1 shows results from our survey that confirm a statement often made about employment relationships in the creative industries: namely that most of the respondents are neither employers in the conventional sense, nor employees, but something in between. It should be noted that the category 'selfemployed' includes project and service contractors, new independents and freelance artists. 'Mobile workers' are people who have several different jobs at the same time.

\section{Figure 1 Employment status by sector and overall $(n=910)$}

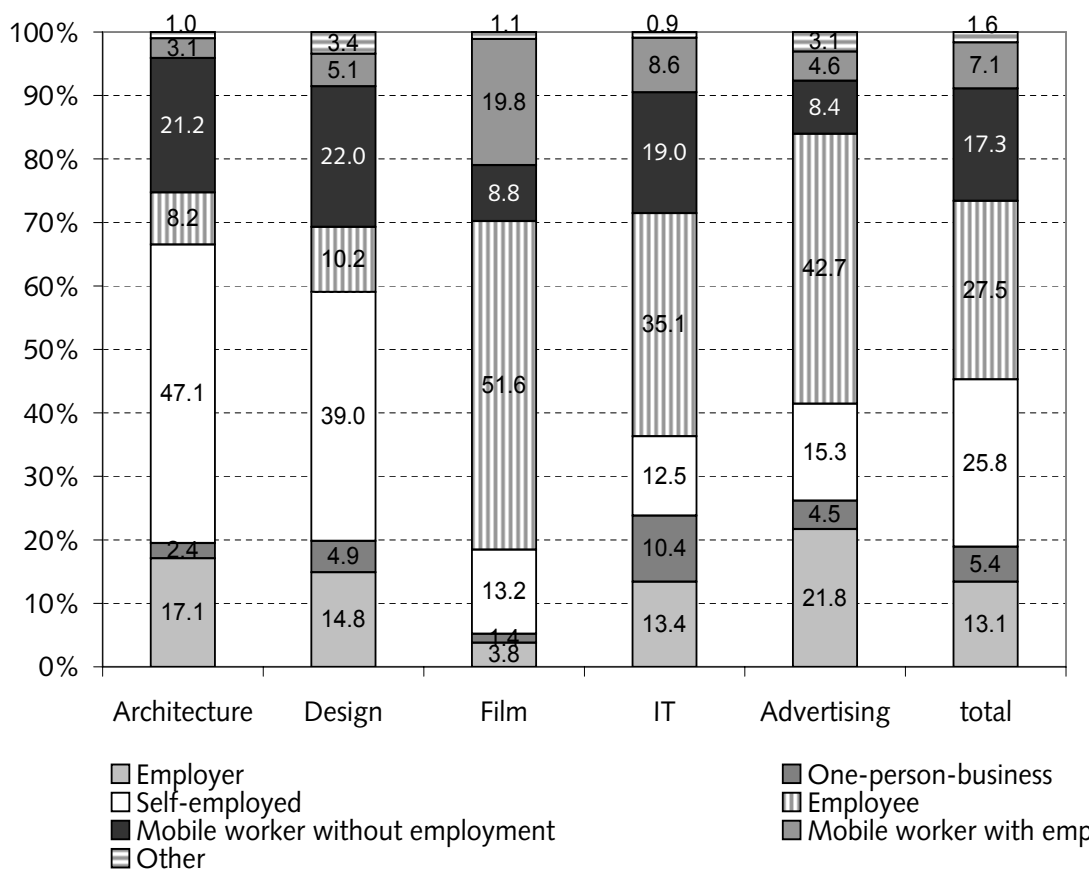

Source: FORBA and Joanneum Research, 2006

It is interesting to ask not only about the employment status of those working in the creative industries but also about what they would like it to be. These results (shown in Figure 2) show that, for the majority of respondents, their current situation coincides with their wishes Those most satisfied with their type of employment are those running their own businesses -90 per cent of these would like to continue to do so in the future. In addition, however, 69 per cent of employees are also in their preferred employment relationship. Only 50 per cent of the self-employed, on the other hand, are happy with their situation. The other 50 per cent would prefer a change -26 per cent would like to run their own business and 21 per cent would like to be employed. Half of 
the mobile workers without employment would like to run their own businesses (most of this group have already set up a company but also have a variety of other forms of employment). In the case of mobile workers with employment, the percentage is somewhat lower, at 42 per cent. Two thirds of this group are already running their own businesses on a part-time basis, and a further third would like to do so. It should be noted that category 'call-off' in the graph refers to a small group of respondents who were interested in obtaining scholarships or Government assistance in their work. Overall, therefore, running one's own business is regarded as preferable to the increased security of long-term, full-time employment.

\section{Figure 2: Current and Preferred Employment Status, in \% ( $n=910)$}

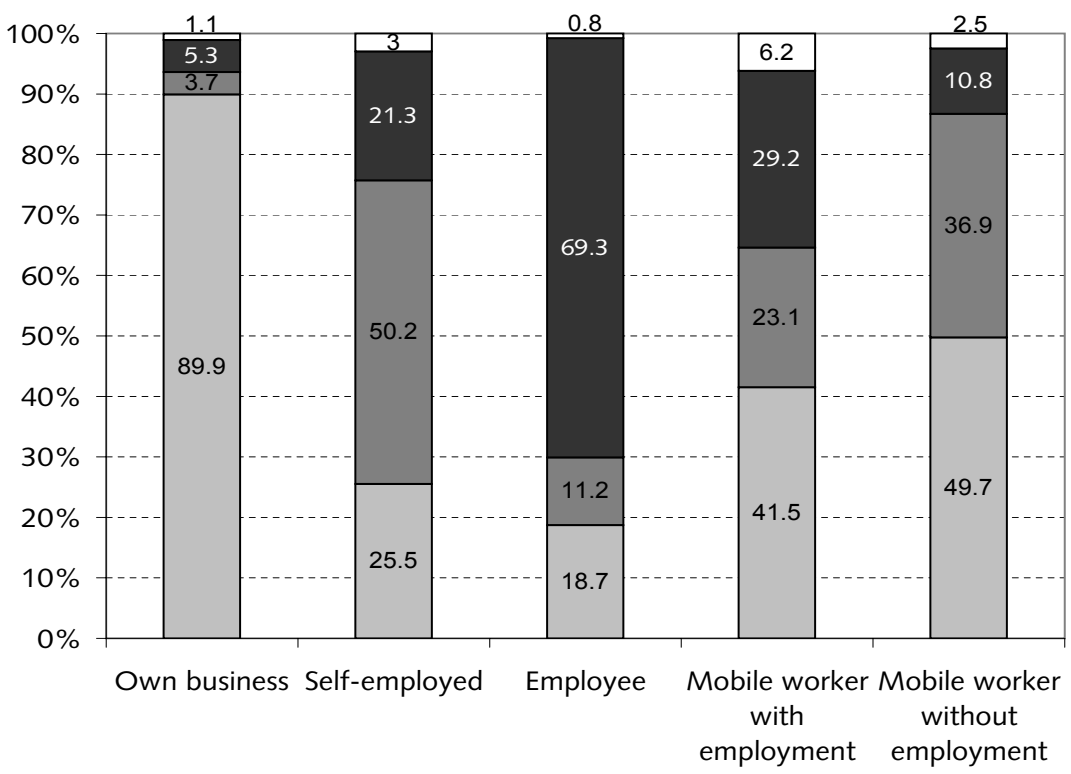

$\square$ own business, co-owner $\square$ freelance $\square$ long-term employment $\square$ call-off

Source: FORBA and Joanneum Research, 2006

Our survey results found people in the creative industries working an average of 44 hours per week. In addition, a quarter of those questioned also worked in other sectors to give themselves some income security. Entrepreneurs, in particular, worked longer hours (52 hours per week inside and outside the creative industries, compared with 44 hours in total for employees). The creative industries also have a high degree of flexibility around when work is done, as Table 2 shows.

In addition to type of employment and working hours, income is a fundamental indicator of the basic (economic) terms on which a job is done. As shown in Figure 3, the average annual net income from work in the creative industries in 2004 was, in the case of these respondents, between $€ 18,000$ and $€ 24,000$. As was expected, there were marked differences between the sectors surveyed, which illustrate the heterogeneity of the five subsectors. Figure 2 shows the income distribution in each sector. Over 20 per cent of de- 
signers earn less than $€ 6,001$ a year (more than in any other sector), and only 10 per cent earn over $€ 36,000$. On the other hand, only two per cent of those in broadcasting earn under $€ 6,001$ a year, and 38 per cent earn between $€ 24,001$ and $€ 36,000$.

Table 2: Specific work practices in the subsectors, in $\%(n=910)$

\begin{tabular}{|l|l|l|}
\hline Subsector & $\begin{array}{l}\text { Weekend work (at least } \\
\text { once per month) }\end{array}$ & $\begin{array}{l}\text { Night work (at least twice per } \\
\text { month after 10 pm) }\end{array}$ \\
\hline Architecture & 72.4 & 58.7 \\
\hline Design/graphics/fashion & 72.9 & 66.1 \\
\hline Film/broadcasting/video & 90.1 & 81.3 \\
\hline IT & 63.5 & 51.6 \\
\hline Advertising & 59.2 & 44.3 \\
\hline Overall & 72.1 & 60.9 \\
\hline
\end{tabular}

Source: FORBA and Joanneum Research, 2006

Figure 3: Annual net income in 2004 by subsector, in \% $(n=817)$

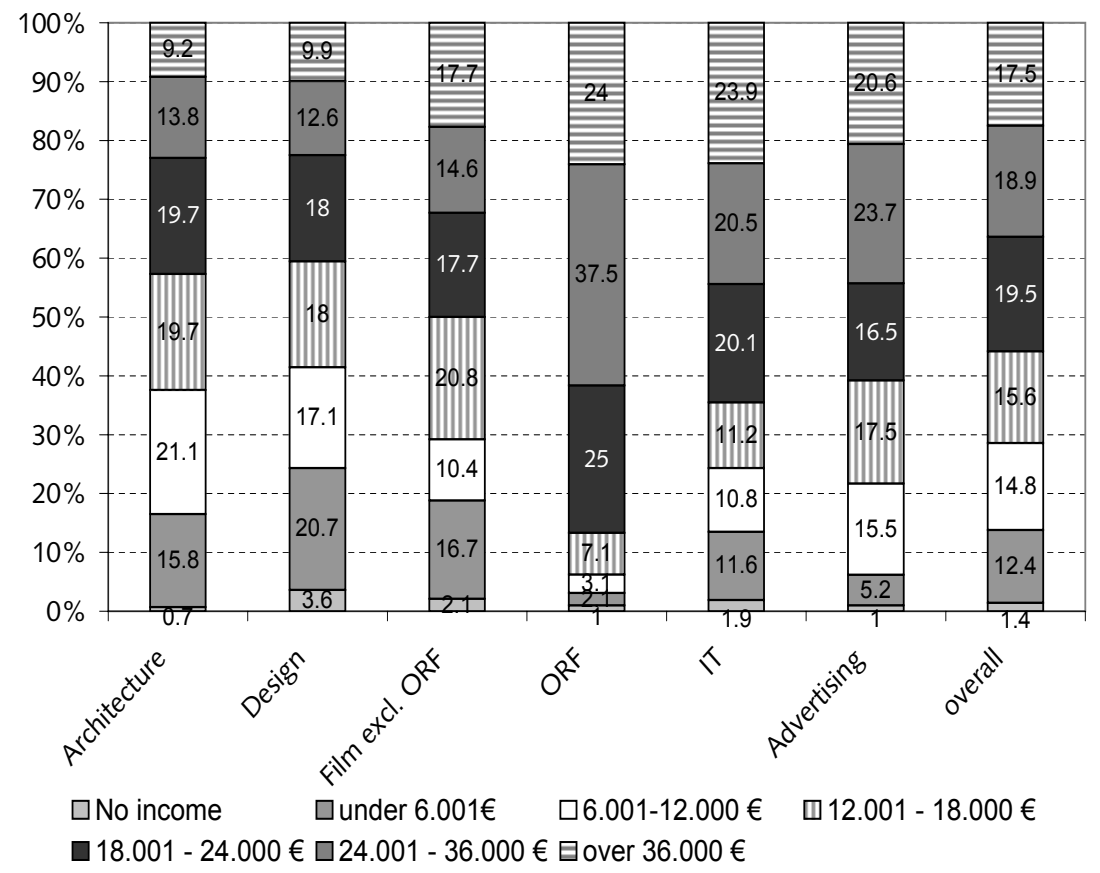

Source: FORBA and Joanneum Research, 2006

It should be noted that many people who earn relatively little in the creative industries work full-time in this sector. Only in the IT subsector do those earning less than $€ 12,000$ tend to be part-time, and the same applies to those in the film subsector earning less than $€ 6,001$. 


\section{Pressures}

A central theme of the study was the pressures felt by those working in the creative industries and how they respond to these pressures. The most serious pressure identified by all those working in the creative industries was time pressure (58 per cent under pressure). Other overriding pressures were concerns about the future, such as the securing of future work (60 per cent under pressure), pension security (58 per cent under pressure) and general personal future financial position (57 per cent under pressure). Overall, with the exception of time pressure, future concerns created more pressure than present ones. Some people, however, also mentioned high personal demands ( 38 per cent under pressure) and the requirement to work on a number of projects simultaneously ( 35 per cent under pressure).

Pressure is increased by several factors: working in a situation characterised by lower fees for the work (primarily as a result of increased competition), uncertainty regarding future work and the resulting inability to plan. These work-related pressures can also affect a person's private life. Many respondents said that working in the creative industries left them too little time for their children and made it difficult to reconcile their work with their private life. This is also evident from the fact that substantially fewer women (less than 30 per cent) than men in the study had children to care for. The results showed that child care is still predominantly a woman's role in the creative industries, with only 30 per cent of the respondents saying that childcare was shared equally between partners.

However, many of the problems experienced by those working in the creative industries are offset by high levels of motivation and independence. People concentrate more strongly on the content of their work in order to forget what can sometimes be unfavourable working terms and conditions. This suggests that (from a subjective point of view) stress may sometimes be experienced as positive. If this ceases to be the case, then psychological and physical problems develop. This is, however, a relatively rare occurrence.

It is also noteworthy that the five subsectors analysed have a lot in common as regards pressures and resources. Two different groupings can be identified on the basis of marked differences between their working conditions and lifestyle: those working in architecture, design/graphics/fashion and film/broadcasting/video outside the ORF (Austrian Broadcasting Corporation) are highly atypical and have difficult working conditions and low income, resulting in greater levels of worry about the future. These people are also more motivated by the content of their work than by material rewards and more frequently place artistic demands uppermost in their career planning. Those working in the ORF, in advertising and in multimedia, on the other hand, have better employment and more conventional working conditions and a higher income.

\section{Resources}

In addition to financial and time resources, which as already noted are differently distributed among the respondents, the survey focused on the social resources and skills used to overcome the various pressures. A distinction can be drawn between 
professional and private coping strategies. Professionally, pressure can be significantly reduced by careful planning ( 72 per cent agree), self-confidence and composure (64 per cent agree) or seeking qualified support in the event of problems (55 per cent agree). Private coping strategies are also important: hobbies (59 per cent agree), long holidays ( 57 per cent agree) or the ability to switch off and not keep think about work during leisure time ( 47 per cent agree) help respondents to overcome the pressures on them.

In addition to these coping strategies, it is also possible to seek support from other people. Asked about the relevance of different 'sources of strength', most seek support from colleagues or through the professional networks on which 81 per cent say they rely. Many respondents also seek support from friends (69 per cent) or their partner or spouse ( 68 per cent). It is striking that 21 per cent of respondents turn to therapists, doctors or coaches for support.

Overall, despite the many pressures they experience, respondents see work in the creative industries as a positive challenge. The majority are motivated by the varied nature of their jobs and by being able to work in a self-determined way. Many have developed a range of professional and private strategies for coping with the pressures. They assess the growth in creative industries over the last five years as positive and expect this trend to continue in the future. The majority of respondents also believe they will always work in the creative industries.

\section{Sustainability in the Creative Industries}

It was necessary to analyse the data in more depth in order to find answers from the data obtained in the survey to questions such as: What does job satisfaction depend on in the creative industries? What creates pressures in the work and what relieves them? And what has the strongest influence on the state of mind of those working in the creative industries? For this purpose, variables were chosen and compiled into various indices which could be used in the next stage of the analysis to draw conclusions about the sustainability of the work.

The four key indicators of the subjective perception of the sustainability of a person's job situation in the creative industries were: job satisfaction; work pressures; respondents' stress levels (state of mind); and planned length of time in the sector.

The extent to which the presence or absence of these resources affects these indicators was investigated. Correlation and regression calculations were made to test which variables have a noticeable effect on these four key indicators. It should be noted here that all the variables integrated into the regression model were used, for reasons of logic and also because of the dependency relationships previously tested (using corresponding correlation measures) in explaining the key indicators.

Analysis of each of these indicators showed that job satisfaction was the one that could be described most clearly with the data available. By contrast, 'state of mind' and 'work pressure' are very difficult to represent numerically, because aspects of social desires and self-image always appear in the answers to the survey. Moreover, it is difficult to relate an unsatisfactory state of mind purely to the work context. Views here are undoubtedly coloured by what is happening in a person's private life. The picture of the 
factors affecting the state of mind and work pressure indices is, therefore, considerably less clear. Three main conclusions can, nevertheless, be drawn overall from this evaluation of employment sustainability.

First, at a micro level, a person's own coping strategies are critical in explaining job satisfaction, pressure and stress levels. Many respondents from the creative industries take it upon themselves to bring about improvements in situations where they are under pressure.

Second, at an intermediate level - particularly in an operational context - ensuring sustainability (measured through wellbeing, satisfaction and elimination of work pressure) through increasing autonomy is critical. It was not so much the continuity of work, but the ability to plan, which is the most important criterion for satisfaction, wellbeing and reduced pressure among those who participated in the survey.

Third, concerns for the future are fundamental as far as sustainability is concerned. Addressing this requires macro level policy solutions. The more uncertainties there are, the more stressed and pressurised the people working in the creative industries feel. It is evident, therefore, that people in the creative industries on the one hand are typical entrepreneurs who organise their own work schedule and are less attracted by being employed in an employee relationship than by independence. On the other hand, they also have a greater need for stability than concepts such as 'new independents' have so far been able to give them.

\section{What does sustainable creative work look like?}

We conclude by asking what sustainability in creative work might look like: what is the profile of the people who currently appear to be working sustainably in Vienna's creative industries? The results of this survey suggest that the 'sustainable creative worker' can be described more or less as follows. Sustainable workers are more likely to be men than women. They are either very young (21-25 year-olds) or of fairly mature years (over 55) and are likely to live in a joint property with a partner.

They work for the Austrian Broadcasting Corporation or in IT or in advertising and are mainly employees, although they occasionally run their own companies. They earn at least $€ 24,000$ net per annum and have extensive freedom to make decisions in their work. They have a whole range of coping strategies for counteracting work pressures both through professional networks and privately. Moreover, they have few concerns about the future. More than other people, they can imagine themselves always working in the creative industries.

(C) Sybille Reidl, Helene Schiffbänker and Hubert Eichmann, 2006

\section{REFERENCES}

Casey, B. H. (1999) 'Employment and Skills in the Cultural Sector' in Cultural Competence. New Technologies, Culture and Employment, eds. Oesterreichische Kulturdokumentation, Vienna: Oesterr. Kulturdomumentation

DCMS, Creative Industries Mapping Document (2001). Retrieved July 27, 2002 from http://www. culture.gov.uk/creative/creative_industries.html 
Eichmann, H., S. Reidl, H. Schiffbänker \& M. Zingele (2005) Branchenanalysen zu Arbeit und Beschäftigung in Wiener Creative Industries. Retrieved June 2, 2006 from http://www.forba. at/kreativbranchen-wien European Commission (1998) Culture, the cultural industries and employment, Brussels Gottschall, K. \& S. Betzelt (2001) Alleindienstleister im Berufsfeld Kultur - Versuch einer erwerbssoziologischen Konzeptualisierung, Zentrum für Sozialpolitik-Arbeitspapier 18/2001. Retrieved June 2, 2006 from http://www.zes.uni-bremen.de Kalmár, M., G. Kernbeiss \& U. Lehner (2005) Kreativwirtschaft: Nutzt Tirol seine Chancen?, Innsbruck: WAW

KMU Forschung Austria \& IKM (2003) Erster Österreichischer Kreativwirtschaftsbericht. Retrieved May 19, 2005 from http://www.creativwirtschaft.at

KMU Forschung Austria \& IKM (2006) Zweiter Österreichischer Kreativwirtschaftsbericht. Retrieved July 7, 2006 from http://www.creativwirtschaft.at

Kulturdokumentation, Mediacult \& WIFO (2004) Untersuchung des ökonomischen Potenzials der 'Creative Industries' in Wien. Retrieved August, 25, 2004 from http://www.creativeindustries.at Lechner, D \& T. Phillip (2006) Kreativwirtschaft in der Stadtregion Linz. Retrieved July 7, 2006 from http://www.tmg.at/1055_DEU_HTML.php

Pongratz, H. J. \& G. Voß (2003) Arbeitskraftunternehmer: Erwerbsorientierungen in entgrenzten Arbeitsformen, Berlin: Ed. Sigma

Reidl, S. \& F. Steyer (2006) Zwischen Unabhängigkeit und Zukunftsangst. Quantitative Ergebnisse zur Arbeit in den Wiener Creative Industries. Retrieved June 2, 2006 from www.forba.at/kreativbranchen-wien

Schiffbänker, H. \& E. Mayerhofer (2003) Künstlerische Dienstleistungen im Dritten Sektor. Teil 1: Ausgangslage: Kunst, Kultur, Beschäftigung. Retrieved, June 10, 2006 from www.equal-artworks.at 